\title{
Temporal tensions: EU citizen migrants, asylum seekers and refugees navigating dominant temporalities of work in England
}

\begin{abstract}
This article considers the role of temporality in the differential inclusion of migrants. In order to do this we draw on research which examined the working lives of a diverse group of new migrants in North East England: Eastern European migrants arriving from 2004 and asylum seekers and refugees arriving from 1999. In so doing we emphasise both distinct and shared experiences, related to immigration status but also a range of other dimensions of identity. We specifically consider how dominant temporalities regulate the lives of new migrants through degrees, periods and moments of acceleration/deceleration. The paper illustrates the ways in which dominant temporalities control access and non-access to particular, often precarious forms of work - but also how migrants attempt to navigate such restrictions through their own use and constructions of time. We explore this in relation to three 'phases' of time. Firstly, through experiences of the UK asylum system and work prohibition. Secondly for a broader group of participants we explore the speeding up and slowing down of transitions to and progression within work. Lastly, we consider how participants experience everyday temporal tensions between paid employment and unpaid care. Across these phases we suggest that dominant orderings of time and the narratives which make sense of these, represent non-simultaneous temporalities that do not neatly map onto each other.
\end{abstract}

Introduction

Under conditions of contemporary capitalism considerable attention has been given to the role of time and speed, particularly the speeding up of everyday life (Harvey, 1989; Virillo, 2004). In relation to work, this is seen to play out through the intensification of employment and 'the tendency for work to colonize the time of life' (Mezzadra and Neilson, 2013: 21) with marginalized groups, including some groups of migrants, particularly exposed (Rogaly, 2008). In this paper we acknowledge not just the speeding up of time, but the co-existence of multiple dimensions of time (Adam, 2004). We suggest that new migrants' working lives are subject to regulation through degrees, periods and moments of acceleration and deceleration. However, these are not experienced passively, rather migrants engage with this regulation as active political agents. Therefore an appreciation of the politics of time (Cwerner, 2001) seems crucial in understanding the challenges faced by migrants. We explore the inter-play between dominant constructions and experiences of time through research examining the working lives of new migrants in the North East of England, including EU citizens from Eastern Europe arriving from 2004 and asylum seekers and refugees from a range of countries arriving from 1999. Our 
This is the accepted version of an article published in Time and Society. For the version of record see: https://doi.org/10.1177/0961463X18778466. To reference: Clayton, J. and T. Vickers (2018) Temporal tensions: European Union citizen migrants, asylum seekers and refugees navigating dominant temporalities of work in England. Time and Society. DOI: 10.1177/0961463X18778466.

attention to those defined through these immigration statuses, allows us to highlight the manner in which dominant temporalities of migration and work shape experiences in both shared and distinct ways. This calls into question rigid binaries, such as 'free versus forced', which often dominate discussions of migration (Lewis et al, 2015), while still retaining recognition of the importance of immigration status as a structuring process.

Initially we outline the conceptual basis of our attention to temporal tensions, with a focus on the role of dominant temporalities in the differential inclusion of migrants in the UK. We then detail our methodology which outlines the basis of our study into new migrant's experiences of work in the North East of England. Through a thematic analysis of qualitative interview data we then conceptualise experiences through what we identify as three key 'phases' of time. Firstly, we examine the experiences of those subject to the UK asylum system as an explicit process of wasted time and prohibition from paid work. The experiences of those going through the asylum process is defined by waiting, suspension and uncertain futures, constructing a clear tension for those willing to contribute and resulting in other forms of unpaid activities. Secondly, we explore the manner in which the employment trajectories of a broader range of participants are produced and navigated through transitions and progression into precarious work. These experiences often entail violent shifts in the rhythms of compulsion to work with consequences for the type of work taken up. Thirdly, we consider flexibility, through the temporal tensions between precarious paid work and unpaid work and lives beyond the workplace. This phase illustrates the forms of sacrifice made by participants across our sample, their limited choices and the need for prioritization in their everyday lives. Across each of these phases we suggest that the multiple dominant orderings of time and the narratives which make sense of these, represent non-simultaneous temporalities that interact, yet do not neatly map onto each other. Whilst there is evidence of opposition, adaptation and resignation, the differential reach of dominant temporalities does not quickly diminish. In conclusion we consider how we might think about both a sensitivity to difference, but also points of solidarity for those who are differentially included.

\section{Dominant temporalities of migration and work}

Time is viewed here as relational. Latour (1996: 181) explains that 'We never encounter time and space, but a multiplicity of interactions with actants having their own timing, spacing, goals, means and ends'. This points to a de-centered characterisation of time that is multiple, complex and neither universally linear nor neatly periodical (Adam, 2004). Similar themes are explored by those who challenge a view of time that is experienced by migrants in an orderly and predictable fashion. For example, Shiubin (2015) argues that timespace is encountered 'more than subjectively' as an open-ended folding of coexisting pasts, presents and futures. Whilst rightly critiquing the view of migrants as rational individualized actors and highlighting the uncertain character of time for those 
This is the accepted version of an article published in Time and Society. For the version of record see: https://doi.org/10.1177/0961463X18778466. To reference: Clayton, J. and T. Vickers (2018) Temporal tensions: European Union citizen migrants, asylum seekers and refugees navigating dominant temporalities of work in England. Time and Society. DOI: 10.1177/0961463X18778466.

'on the move', there is also a need to more explicitly explore how dominant versions of time condition experience, thus (re)producing such uncertainty. As Latour (1996) infers, there is a politicization to time as differentially conceived and organised, through the distinct 'timings, spacings, goals, means and ends' (181) he mentions. Griffiths et al (2013) indicate that tensions emerge from this very co-existence of distinct temporalities. Time is thus encountered through uneven power relations, material conditions and established inequalities (Rogaly and Thieme, 2012). As with scholarship on the manner in which b/ordering works through political projects that spatially organize, control and racialize migrant bodies through the 'relational state' (Yuval-Davis et al., forthcoming), dominant temporalities are produced by, but also productive of, forms of 'differential inclusion' into national economies and polities (Mezzadra and Neilson, 2013).

By 'dominant' we refer here to temporalities that have a significant degree of determination over the manner in which time is both viewed and experienced. These may be multiple and differentially encountered, yet share a capacity to organise pasts, presents and futures as well as everyday routines. Powerful versions of the past may linger in the present, such as the post-colonial melancholia of lost Britishness that Gilroy (2005) identifies. Or as Baldwin (2012) argues, with reference to whiteness, dominant visions of the future might ensure the protection of racialized privilege and oppression. Dominant temporalities might also be seen to order and control diverse experiences through what Griffiths et al (2013: 30) refer to as 'temporal devices and rationalities'. They may require individuals to conform to normative versions of life-stage (Taylor, 2010); gendered divisions of paid and unpaid work (Wajcman, 2008) or to expectations of career stage 'to group, regulate and maximize productivity' (Hargita, 2016: 226).

Specifically in relation to migration and work, the UK asylum system is characterised by strict regulation, akin to other carceral spaces where inmates are subjected to 'clock-time' and stasis (Moran, 2012). This takes various spatial forms, from the regimented institutionalised clock time of detention centres to the limbo of awaiting the outcome of an asylum claim while in 'the community' (a no-choice residential location) and restricted from accessing employment and education. The indefinite duration of both detention and the asylum claim process deepen the sense of spatio-temporal incarceration and subjection. Cwerner (2004) considers how dominant institutional tempos clash with the life narratives of migrants from the start of this process, through the initial interview asylum seekers are subjected to upon arrival. With its' focus on swift processing, he suggests that time is used as a deterrence and a tool to restrict the case of the individual. Additionally, delay, rejection and stasis are incorporated through incorrect rejections for support, extended periods in reception accommodation, delays in accommodation, and indefinite detention (Refugee Action, 2017). Processes of differentiation also affect EU migrants, despite 'free movement'. Along with other 'hostile' measures introduced to restrict the rights of European migrants to claim welfare support, from 2014, those 
This is the accepted version of an article published in Time and Society. For the version of record see: https://doi.org/10.1177/0961463X18778466. To reference: Clayton, J. and T. Vickers (2018) Temporal tensions: European Union citizen migrants, asylum seekers and refugees navigating dominant temporalities of work in England. Time and Society. DOI: 10.1177/0961463X18778466.

moving from EEA countries ${ }^{1}$ must have been resident in the UK for three months before they could claim Job Seekers Allowance. EU migrants can be deported on the basis of 'economic inactivity', and in May 2016 grounds for deportation were expanded to include even a single night spent sleeping on the street. This creates an accelerated transformation from actively employed mobile citizen to deportable object. It is through such strategies that 'governable mobile subjects' are produced (Mezzadra and Neilson, 2013), subjected to delay and acceleration that facilitate desired economic and political 'integration' (Anderson, 2009), but also dictate the shape of imagined futures (Ylijoki, 2010).

Much of the scholarship concerned with the temporal dimensions of migration and employment, focuses on how tempos of working lives are conditioned by state policy. The connections between immigration policy and differential inclusion into paid employment are underpinned by a central contradiction where 'The migrant is the person necessary to but restricted from advanced capitalist societies' (Hall, 2017:1562). Bloch and McKay (2016) note how deregulation, sub-contracted work and casual employment have facilitated migration not just because of, but in spite of stricter immigration policies. There then exists a tension for states in the symbolic and physical process of control over racialized borders where greater value is attached to those seen as rooted in place, whilst simultaneously regulating the workforce in line with the needs of capitalist economies. This requires some forms of mobility to be valued on economic terms.

However, as Anderson (2010) points out, immigration controls do not only regulate movement but also rights once the physical border is crossed, thereby helping to fashion sections of labour that are susceptible to exploitation in particular ways. This results in both shifting and contradictory processes of othering (Vickers and Rutter 2016) and situations where workers are moved into and out of employment at speeds which can be delayed and drawn out, but also speeded up and subject to demand at short notice (Pjipers, 2011). Anderson (2007:8) shows how strict immigration controls 'mould' hyperflexible workers and labour temporalities - processes in which working time, length of contract, length of stay, life stage and changing immigration status are key. Mezzadra and Neilson's (2013) concept of the 'temporal border' usefully unpacks the manner in which rather than acting to block the movement of migrants, various techniques, including detention, points-systems and 'benching' are a means of regulating 'the time and speed of their movements into labour markets' (p.132). They imply that there are unique temporalities at work for migrants 'where the compression, elongation and partitioning of time exerts effects of control, filtering and selectivity' (p. 132). Borders then 'differentially include' through the production of 'differentiation and stratification of legal statuses and subjectivities' (Andrijasevic, 2009:16). The fact that migrants in the UK are

\footnotetext{
${ }^{1}$ This includes all EU countries as well as Iceland, Liechtenstein and Norway.
} 
This is the accepted version of an article published in Time and Society. For the version of record see: https://doi.org/10.1177/0961463X18778466. To reference: Clayton, J. and T. Vickers (2018) Temporal tensions: European Union citizen migrants, asylum seekers and refugees navigating dominant temporalities of work in England. Time and Society. DOI: 10.1177/0961463X18778466.

dis-proportionately positioned in lower paid and lower status work than the general population (Bloch and McKay, 2016) means they are particularly exposed to levels of insecurity (Shildrick et al, 2012), precarity (Waite, 2009), and spatio-temporal uncertainty. This implies limits of control over work and other aspects of everyday life, especially those whose rights to reside, work and access public support are severely constrained or have been terminated (Lewis et al, 2015).

It is also clear that the manner in which time is ordered creates a number of tensions for individuals who can never be defined solely in relation to employment or ascribed immigration categories. This seems particularly important when we look at the ways in which working time connects and clashes with other aspects of everyday life - such as leisure time, household tasks and caring responsibilities. As Tsianos and Papadopoulos (2006) argue, the shift to Post-Fordism has resulted in a lack of security in relation to working and non-working time: 'Precarity means exploiting the continuum of everyday life, not simply the workforce. In this sense, precarity is a form of exploitation which operates primarily on the level of time'. This is particularly important in relation to the balance between the temporalities of paid work and unpaid care. As Dyer et al (2011) and Datta et al (2007) explain, there is limited evidence for the use of formal childcare by migrants thus generating an increased responsibility to bring in an income and arrange for forms of informal care - referred to as the 'double shift' (James, 1972) of productive and reproductive work. This would seem to be particularly problematic for women without established social networks, and draws attention to differential inclusion on the basis of not only immigration status, but also geographical location, length of residence and gender.

The extent to which dominant framings of time come to be imposed and/or resisted also requires attention. While dominant temporalities are overbearing, potentially damaging and may seep into experiences as a form of governmentality (Moran, 2012), they also have diverse consequences, are contextual and do not command lives as a totality. Alternative times or what Huebener (2016:248) calls 'non-dominant temporalities' might be mobilized as a way of 'interrupting, resisting and challenging the normative and hegemonic temporal framework'. Axelsson et al (2017) for example, show how Chinese chefs in Sweden respond to uncertainty through strategies that have short-term adverse consequences for working conditions, but may offer better longer-term chances of geographical and employment security. In other work responses are more overtly collective, through claims to citizenship that contest the positionality of migrants as produced through immigration controls (Andrijasevic and Anderson 2009). It is therefore crucial to recognize the 'construction of subjectivities in relation to both oppressive and affirmative power dynamics' (Andrijasevic and Anderson, 2009: 366).

Methodology 
The research upon which this paper draws, explored the position and experiences of new migrants in the North East of England. This was a co-produced study (see Clayton and Vickers, 2017) conducted in partnership with two partners in regional voluntary and community sector organisations (Regional Refugee Forum North East and International Community Organisation of Sunderland). We were interested in exploring the position and experiences of both EU citizen migrants arriving after $2004^{2}$ and asylum seekers and refugees arriving since $1999^{3}$ in our definition of 'new migrants'. These migrant categories were selected because they have all been stigmatized, have had their mobility problematized by significant sections of the media and political establishment, and exhibit concentrations in various forms of precarious and low-paid work and worklessness. However, it is also recognized that there is significant diversity between and within such politically constructed groups (Middleton, 1999). We were therefore interested to explore both distinct and shared experiences.

We adopted a mixed-methods approach, drawing on Phillimore and Goodson (2006) and Bloch (2007); this included a survey $(n=402)$, qualitative interviews with migrants $(n=40)$ and other stakeholders $(n=12)$, and a policy seminar held towards the end of the project $(n=50)$. The survey gathered data on objective indicators of labour conditions (reported in Vickers et al., 2016). More experiential dimensions were explored through the qualitative interviews with migrants. The stakeholder interviews and policy seminar supported internal verification by reflecting on and providing feedback on how initial research findings tallied with or deviated from their own situated knowledge. This article draws primarily on the migrant interviews, although also employs aspects of stakeholder interviews where this contextualizes migrant narratives. The interview sample was broadly distributed by locality, gender, age, immigration status and country of origin. 15 respondents were men and 25 were women, 14 were EU10 migrants, 17 refugees with leave to remain (including some with British citizenship), 8 were asylum seekers (some of whom had been refused asylum), and 1 was a non-EU spouse of an EU citizen. It is important to recognise that as we accessed participants mainly through migrant support organisations (Clayton and Vickers, 2017) our sample were most likely neither amongst the most integrated nor the most excluded in the region.

As Griffiths (2014: 1994) explains, the focus on time, temporality and speed here is not an attempt to artificially generate a novel way of conceptualizing experiences. The impetus comes from the fact that as in Griffith's research time was 'a salient means by which [participants] themselves conceptualise uncertainty and disruption'. This focus emerged inductively through thematic analysis (with the use of N-Vivo qualitative data

\footnotetext{
${ }^{2}$ When the 'A8' countries in Eastern Europe joined the EU, followed by the 'A2' countries in 2007.

${ }^{3}$ When the UK government initiated a 'dispersal' scheme that resettled asylum seekers to the North East

England and other parts of the UK.
} 
This is the accepted version of an article published in Time and Society. For the version of record see: https://doi.org/10.1177/0961463X18778466. To reference: Clayton, J. and T. Vickers (2018) Temporal tensions: European Union citizen migrants, asylum seekers and refugees navigating dominant temporalities of work in England. Time and Society. DOI: 10.1177/0961463X18778466.

analysis software), but was also built into the research design with attention to employment experiences prior to and since arrival in the UK. We recognise some of the limitations of one-off interviews as a means of capturing change (Robertson, 2015), yet in recognition of the relationality of time, we suggest that asking individuals to reflect on their pasts, presents and possible futures, offers a suitable means of accessing how subjective temporalities are constructed in the light of, or in spite of, dominant ordering. By paying closer attention to these experiences we can appreciate how distinct, conflicting and intersecting temporalities are at play, where 'Echoes of the past and uncertainty about the future invade a present in which experiences of life and techniques of measure at once overlap and clash' (Mezzadra and Neilson, 2013:134). We now move on to explore the key tensions emerging from our data through three distinct yet interconnected phases. ${ }^{4}$

\section{Navigating times of employment prohibition}

Some experiences of dominant temporalities amongst our participants were distinguishable by state-sanctioned treatment based upon specific immigration status. We therefore focus firstly on the experiences of those exposed to the UK asylum system as a clear illustration of this. By facilitating forms of (non) entry into paid work we show how the asylum system highlights tensions between the temporalities of immigration and work. This is an ordering that restricts which type of labour is allowed against desires to 'contribute', in a context where waged labour is valued more than other forms of activity (James 1972) and those removed from waged labour are consequently devalued.

For some asylum seekers and refugees we interviewed, the experience of asylum was explicitly viewed in terms of deterrence and punishment. This related to literal incarceration, for example in immigration detention centres (Turnbull, 2016), or the 'intimidating' initial interview that Cwerner (2004) suggests is characterised by speed. However, participants did not reflect on this aspect of their experience as rushed, but rather as drawn out. Beyond the interview there was an impression that obstacles were manufactured which prevented progression to a secure status and therefore access to formal paid work. Examples included experiences of refusals such as Natalia's (Female, 30s, from Zimbabwe), which on appeal was dismissed by judges as a 'waste of time'.

Following an asylum application, one of most commonly articulated experiences was of being in 'limbo', of waiting for a period of time whose length was unknowable and during which the right to work in paid employment was suspended (Andersson, 2014). The withdrawal of such a basic human right, is seen by Marie as a violent act (Canning, 2017):

\footnotetext{
${ }^{4}$ We use the term 'phase' here rather than 'stage' or 'period' as an attempt to capture the non-standardized and non-delineated experience of time expressed by our participants.
} 
This is the accepted version of an article published in Time and Society. For the version of record see: https://doi.org/10.1177/0961463X18778466. To reference: Clayton, J. and T. Vickers (2018) Temporal tensions: European Union citizen migrants, asylum seekers and refugees navigating dominant temporalities of work in England. Time and Society. DOI: 10.1177/0961463X18778466.

Do you want to work or you want to stay on support? Most of them answer: I want to work...I don't know how they are going to do it, whether they will even do it because it's part of punishment. It's a real punishment telling someone who is used to working, not to work. (Female, from Gambia, waiting for decision)

Not all participants who sought asylum had to wait long periods, although many were waiting or had waited up to 10 years on minimal state support. Several participants had appealed their refusal, extending uncertainty and entailing a heightened fear of among other things, deportation and/or destitution (Bloch, 2014). The experience of not knowing either how long this period would be or the outcome, left some in degrees of what Griffiths (2014) calls 'suspended time'. Amina (Female, from Pakistan) for example talks about the difficulty of this open-ended suspension of rights and known futures: 'I'm still waiting and you're just kept in suspense, you're just there waiting, you don't know when it will end. So it's hard.'

Whilst Ylijoki's (2010) work explores the accounts of those in very different circumstances (short-term academics), there are parallels here with a future orientation of 'instant living' (376-377), where the future is 'bracketed off' to focus on the present, and 'remains to a great extent unpredictable and beyond individuals' own control and intervention.' This had significant implications for mental health, particularly for those who had already experienced trauma. In the case of Rachel we glimpse the extremes of what it means to wait indefinitely. Lack of access to work is a major element of this differential inclusion, entailing a highly constrained form of liminal citizenship - where she is present, but 'stuck' (Griffiths et al, 2013).

At first I thought well it was a joke, but when you come to reality you couldn't be allowed to apply for any jobs, or like do anything, and that made my life hell, from there on. I didn't know how to live, without going to work, and what do I do, you're just looking at the situation and think ok what am I supposed to do the whole day, in the house...I've never not worked, at all, and just to be there, in that house, whereby you know you don't know anybody, except for the people who were my neighbours...It was just an emotional torture, an emotional damage, I'm sitting here crying, and I'm sitting here everyday thinking ok God I'm here, but what's my future? I don't even know whether I'm going to be given the status or not, and I don't know what's happening to my children because they're in another country where I can't even go because I don't have my passport...and I am just stuck here. (Female, from Zimbabwe, indefinite leave to remain) 
This is the accepted version of an article published in Time and Society. For the version of record see: https://doi.org/10.1177/0961463X18778466. To reference: Clayton, J. and T. Vickers (2018) Temporal tensions: European Union citizen migrants, asylum seekers and refugees navigating dominant temporalities of work in England. Time and Society. DOI: 10.1177/0961463X18778466.

The absence of opportunities to work meant Rachel was consigned to going nowhere and doing little with her time. This was compounded by separation from her family. We also see the clear contrast between a life in which she had 'never not worked', and the reality of what claiming asylum in the UK entailed - articulated here as a 'joke'. The tension between restriction and potential trajectory is central to her suffering.

Others articulated this experience of 'wasted time' in terms of societal contribution. Ebrima's narrative represents a non-linear temporal progression. He arrived on a work visa with his wife, and worked for years as a hospital porter and then in various care homes. On returning to the UK after visiting his mother and following allegations against him, his right to enter the UK expired. UK state officials suggested he apply for asylum and he found himself unable to work. Nothing had changed in terms of his ability to carry out paid work, aside from the fact that he was now re-positioned through his new status as an 'asylum seeker'.

I should be useful. I [could] work in care homes, I should be... Even if that is the work I should be doing that, I should be caring somebody. Well I don't like sitting here on asylum, basically for nothing...You have to be productive...I should be productive, I should be happy, I should want to do something. You know, I should be contributing to the development. And I've been in UK all this long, I've never claimed asylum. I've never claimed benefits. I'm not interested in claiming benefits. And if you have leave [to remain], tomorrow I tell you I will have work. (Male, from Gambia, refused asylum)

For some, this imposed wasted time was too much. Whilst limited, there was evidence, supported by knowledge from key informants that spoke to realities of 'hyperexploitation' outside of the formal economy (Lewis et al 2015). However, not all participants expressed ardent opposition or resistance to this period of enforced waiting. Others reflected in terms which were more acquiescent. As Turnbull (2016) suggests, certain forms of waiting leave some with little sense of agency and compliant to the demands of uncertainty. For example, Kevin seemed to accept the fact that he was unable to work legally during this period of waiting. This clearly had implications for how he imagined his future as yet to fully 'unfold'.

You get through a lot of experiences, which at the moment personally I don't want to go through any experience. I just would prefer to be private and focus on what is going on and see how it will unfold. (Male, from Kenya, refused asylum)

The ability to see a future is easier for those that have a degree of security in the present (Clayton, 2009). This of course does not mean that people do not project, hope or dream 
This is the accepted version of an article published in Time and Society. For the version of record see: https://doi.org/10.1177/0961463X18778466. To reference: Clayton, J. and T. Vickers (2018) Temporal tensions: European Union citizen migrants, asylum seekers and refugees navigating dominant temporalities of work in England. Time and Society. DOI: 10.1177/0961463X18778466.

in relation to the places in what they find themselves (Raffaetà, 2015) - but these aspirations can also be stunted, hidden or re-directed. The past also plays a crucial role here - traumatic pasts feed into this lack of willingness to look too far forward. For Kevin there is a desire not to compromise his position, given those 'experiences' alluded to.

However, as Rotter (2015) suggests it is important to acknowledge that such waiting time is not necessarily wasted in the sense of being empty. Such experience can also exhibit affective, active and productive dimensions. In our own research, alternative temporalities were mobilized and demonstrated the capacity to make the best/different use of prohibition. This involved personal as well as community development. Despite her frustrations, Marie (female, from Gambia, awaiting decision) explained how she negotiated access to a college which covered childcare costs 'to keep me busy'. In addition to formal education, which for some was more restricted, others volunteered as a means of filling time, learning skills and language and developing friendships (also Vickers 2016). Although such contributions could involve 'professional' skills, they were not valued in the same way as waged labour with regard to either status or reward. Amina works up to 7 days a week, 9am-5pm as a liaison between asylum seeker families and the public sector. In addition, she works in a finance department for a charity. While these opportunities are clearly significant, this work is unpaid and the sense of feeling undervalued, but also criminalized is palpable. Her status as an asylum seeker fixes Amina's value both materially and symbolically as an undesirable figure, peripheral to the nation and formal workforce.

So, it is useful, but on the other hand I just feel like after doing all of this voluntary work I still get five pounds a day and I still have to look at other people's face to get this help, and believe me, when I go to collect my weekly support, I feel like I'm not a beggar. And when they look at you they look at the card and then they look at your face, you feel like I'm not criminal...Without pay I'm doing all of this. I can get a good pay if I'm allowed to work. Please don't look at me like this. (Female, from Pakistan, waiting for decision)

Navigating speeds of transition and progression into paid employment

We move on here to explore the manner in which transitions into work and employment progression represent a distinct temporal phase, both for those given some form of leave to remain following their asylum application, but also for EU migrants in our study. In some instances, immigration status and welfare regulations had a powerful effect in accelerating movement toward work, and this influenced the kinds of work that were accepted. Related to this, the transition to paid work was marked by the ongoing de- 
This is the accepted version of an article published in Time and Society. For the version of record see: https://doi.org/10.1177/0961463X18778466. To reference: Clayton, J. and T. Vickers (2018) Temporal tensions: European Union citizen migrants, asylum seekers and refugees navigating dominant temporalities of work in England. Time and Society. DOI: 10.1177/0961463X18778466.

valuation of skills. Whilst the experience of asylum was often seen as lengthy and drawn out, for many of those transitioning to mainstream benefits after receiving some form of leave to remain, the experience was characterised as speeding up too quickly, an unsettled and frenzied (Griffiths et al. 2016) shift.. A key informant in welfare rights discussed the window (of 28 days) in which refugees are expected to move from separate asylum support systems to mainstream welfare, housing and search for work as 'not enough'. The contrasting rhythms and conditions of not being allowed to work and being compelled to work are stark. The impact on levels of confidence to secure work in the future is clear.

When you tell people like me and many others, we used to be very busy, have their own cars, go to work, come back home, have their own responsibilities, taking care of their homes. You come here they will tell you, no, you cannot do that anymore you have to stay at home, you cannot...you have to be very strong to be outgoing. To gain your confidence back...I still struggle. (Marie, female, from Gambia, awaiting decision)

Driven by policies of conditionality and personal responsibility (Wright, 2012) and a discourse of migrants as a threat to public resource (Gedalof, 2007), once deterrence is no longer an issue, compulsion to work quickly is the dominant force. However, many participants found it hard to secure initial employment. Some are caught in what we might view as a time trap, particularly in relation to a lack of evidence of experience in the UK, even if they have sector specific experience in other contexts. In addition to issues of confidence, Kati identifies a lack of UK based or sector based experience, rather than specific qualifications as one of the main challenges. Without the ability to gain that initial opportunity there is little chance to accrue such experience. This transition is therefore often marked by unemployment or employment into more precarious work.

The things they are asking for, it's not about the qualifications, you have like training for mental health employability, there they are always looking for experiences. Yes, experiences, you have to have six months' experience, one year experience, and if I was allowed to work here, I would never have experience in that kind of work...So that is the problem, having experiences and even having the confidence. (Female, 40s, from Gambia, temporary leave to remain)

For others access to paid work occurred more quickly, but there was a clear contrast between the kind of work that some were voluntarily engaging in on an unpaid basis and the work that was available to them through, for example recruitment agencies - one of the quickest, but most exploitative avenues into paid work (Sporton, 2013). 
For EU migrants, the pressure to find any work as quickly as possible, partly as a result of restrictions on state support for the first three months in the UK, defined many experiences. For Jan, originally from Poland, such changes to eligibility for state benefits influences the changing time frame in which work needs to be secured and therefore his reliance on recruitment agencies.

If you go directly to the employer, you've got less chance to do it, to do... to get... to get any jobs. If you go to the agency, they always find you a job and quite fast, especially when I need to... when I need to do any job to get money straightaway, because....when we get back to Poland and we came back, I suspend all social benefits such as tax credits and child benefits, so when we came back, we need... I need... I need... I need to... I need to... pay job, because to start it again. (Male, 30s, from Poland)

Even for those participants working in familiar sectors, status, pay and conditions were generally inferior to those experienced in prior countries of residence. As Mezzadra and Neilson (2013: 141) suggest in their critique of the concept of 'de-skilling', 'cross border mobility often spells a radical devaluation of their competencies'. This experience of devaluation was summarised succinctly and evocatively by Ruth (female, from Democratic Republic of Congo, indefinite leave to remain) when she stated: 'I'm big, but here I'm small. I think nobody can see me'. There was some evidence in our survey that pay progressed in relation to the length of time lived in the UK ${ }^{5}$, but there was also qualitative evidence of participants becoming 'stuck' in low paid work that had been initially taking up in the period after leave to remain had been granted or for EU migrants, either before arrival in the UK or shortly after migration. Helena, for example, refers to the fact that despite the clear opportunities presented by moving from Poland in 2010, she didn't anticipate that she would be working in a factory several years on - a role for which her previous qualifications and learning experiences were of no clear value. The under-valuing of competencies in combination with the speed of transition into employment - any employment should could find through her contacts - has entailed a situation for Helena that results in little sense of progress.

I lived there for two weeks and I worked there in an Italian Restaurant in the pub but I don't have the good experience you know, I don't know good the menu so I just make the drink and take plate and you know, when the people finish eat, so I worked there for two weeks and after we coming on the north and I start working in a factory with ice-cream but I'm not enjoying this place when I work so... but now I just work there. (Female, 20s, from Poland)

\footnotetext{
${ }^{5}$ Median wages increased to $£ 9.55$ per hour for those arriving before 2003 (Vickers et al. 2016).
} 
For some participants, work-based identities are subject to radical re-fashioning, what Bauder (2003) refers to as 'brain abuse'. Various combinations of barriers - including immigration status, language, gender, familial responsibilities, discrimination, education and recognition of skills and qualifications - limited participants in accessing the kind of employment they considered appropriate to their prior skills and experiences, or in some cases any employment, and meant that they had to start their careers afresh. This is a challenge to the idea of linear progression, but also communicates a sense of wasted energy and lost time especially when contrasted against a willingness to work. This is all the more difficult for some because of the stark differences in time frames, between the time taken to accrue skills and qualifications and the much shorter time in which these become useless or irrelevant. It is this cliff edge that results in such a violent impact. Gabi illustrates how even those with very niche and skilled backgrounds can struggle to translate those to the new UK context, in this case largely because securing work in photography requires a strong and established social network. This seems to be of particular significance in a saturated UK job market. Given Gabi's route to employment in the UK through factory and then care work, involving long hours, the ability to establish such networks has been severely compromised.

Well, my profession is one in which you have to be very, very good in order to get a job, anywhere in the world. But before I came to the UK, I was, my last job was as Picture Editor at a newspaper. I was working only in the office, and also on location taking pictures, selecting the pictures, the daily and weekly prints. And moving here, there's a big change because the market is full, and obviously I didn't have the right connections to get even near to the press. So I've been working in factories and warehouses, and I ended up in the care industry. (Male, 50s, from EU10 country ${ }^{6}$ )

One way of coping with such transitions is to 'move on'. This relates to physical migration within the region, the UK and sometimes beyond, but also referred to educational progression. Responses included a sense of determination and resolve to try and achieve what is required to improve lives in the UK, for the participants and/or -especially for those with children - their families. This was often expressed with a focus on improving English language abilities ${ }^{7}$. Some of those with lower levels of confidence in using the English language viewed this as something that needed to be initially addressed before any other barriers. This determination to progress was often related to gaining qualifications that would allow individuals to pursue vocational pathways. However, the promise that (re)education would be a route to employment didn't always materialise quickly or straightforwardly. The ability to progress is a matter of time - time which is

\footnotetext{
${ }^{6}$ Due to the very specific nature of the job discussed here, the home country of this participant is not disclosed to secure anonymity.

${ }^{7}$ This was identified as the primary barrier in accessing employment in our survey.
} 
This is the accepted version of an article published in Time and Society. For the version of record see: https://doi.org/10.1177/0961463X18778466. To reference: Clayton, J. and T. Vickers (2018) Temporal tensions: European Union citizen migrants, asylum seekers and refugees navigating dominant temporalities of work in England. Time and Society. DOI: 10.1177/0961463X18778466.

hampered by the demands of immigration policy, employment practice, but also other demands of everyday life - which we will go on to consider in more detail.

Navigating flexibility: tempos of employment and family life

Whilst there was a widespread desire across our participants to access employment, it was also the case that work, where obtained, was often 'flexible' and precarious, placing some participants in positions of exploitation and extreme insecurity. This was the case for those across our sample including people of various immigration statuses. For example, Henryk here discusses his treatment as disposable labour, in which neither his past nor future were valued.

I've been waiting 10 months and then I asked an Englishmen in an agency about my workplace, shouldn't they change my sector and I don't know, the next day I was told that they don't need me anymore. They got rid of me, they booted me out... (Male, 40s, from Poland)

The flexibilisation of work was also viewed negatively in light of a desire to work more hours and a willingness to take most kinds of work that paid given other barriers reported. Despite this, individuals pro-actively managed their time in ways which mitigated some of the negative effects of insecure and low paid work, including taking up multiple jobs and extending working hours where possible. However, this was often limited to those without caring responsibilities, or whose caring responsibilities could be taken on by others. For some families the impact of longer working hours disrupted family relations and enforced long unpaid working hours, particularly for female family members. Gabi illustrates these pressures here:

It's too much, because I'm a family man. My son is that age when I would like to spend as much time as possible with him. But there are weeks when from Friday evening until Tuesday afternoon, I don't see him. When we moved down from [town in north of region] to [current city] and I started these long hours, one day my wife phoned me and said, your son asked if you're coming home. (Male, 50s, from an EU country)

There were specific experiences articulated by participants as new arrivals, women with children and individuals who had been isolated socially and economically. For some participants from EU countries (particularly Romanians during the transitional period), recruitment to employment agencies took place in their home country, tying them into fixed contracts and shared accommodation - placing constraints on job mobility, but also separating them from their families. As we have seen, familial separation also occurred for those seeking asylum - but in very different contexts and usually on a longer term 
This is the accepted version of an article published in Time and Society. For the version of record see: https://doi.org/10.1177/0961463X18778466. To reference: Clayton, J. and T. Vickers (2018) Temporal tensions: European Union citizen migrants, asylum seekers and refugees navigating dominant temporalities of work in England. Time and Society. DOI: 10.1177/0961463X18778466.

basis. However, both illustrate a gendered sacrifice made by those who anticipated that migration would entail such social costs.

For other participants with children in the UK childcare had a crucial role to play in influencing the terms on which participants engaged with the labour market. Indeed, those with caring responsibilities, were more likely to want to access temporary rather than permanent work which fitted around these needs. However, the issues of lack of control over when these hours of work were and the predictability of those hours still applied. As Kati explains below, a lack of support, along with a lack of flexibility (which might put her in control of the rhythms of her life, rather than her employer) was a crucial barrier to accessing work which suits the available hours given her sole caring commitments for her daughter. Kati explicitly demanded temporary work - this was in theory an arrangement that suited her family life and caring requirements, but this did not necessarily entail a lack of certainty or daily schedules that suited her.

If I was back home with my daughter there, I wouldn't have any problem for somebody looking after her, for me to go to work at any time in the night. But I cannot do that here, because I am the only one looking after her here, so what job I go for, like I go for a temporary, I go to a temporary agency and say that I am looking for temporary work in the factory or something, and they took me in, but I have to start from six in the morning, and I have a twelveyear-old daughter. (Female, 40s, from Gambia, temporary leave to remain).

As has been explored by Dyer et al (2011), in the context of low paid migrant workers in London, it is challenging for some migrant mothers to find time to establish their own familial caring strategies. Working times are often incompatible with the times of life outside of paid employment including other forms of unpaid labour, but also other commitments to family, community and broader social networks which in our study extended beyond national boundaries through regular communication, forms of transnational childcare (Dyer et al, 2011), and the transfer of remittances (Ryan, 2008). We recognise that this incompatibility is not something solely experienced by new migrants and is certainly an area where forms of solidarity may be mobilised across and within social groups. However, for participants in our study these conditions were exacerbated through an intersection of immigration status, forms of institutional and inter-personal discrimination and for many a lack of established social networks especially significant in relation to childcare options in a region where ethnicity-based networks are not so historically embedded. As Datta et al (2007) outline, the use of ethnic networks is a fragile yet important source of childcare support, especially for those with little knowledge of what formal provision might be available. New migrants in particular therefore, especially those whose place and timing of residence is based on degrees of compulsion, may find themselves particularly affected. 
Even for those with children who had partners living with them in the UK, gendered divisions of labour, incompatible work routines and the mis-match between the labour of paid work and childcare, meant that the slots where paid work could be taken were extremely restricted. In their study Datta et al (2007) found a low level of take up of shift work amongst migrant women in London, but below Natalia talks about the way in which she has been forced into a situation of having to take night shifts on the weekend in order to manage and strategize around such limitations. Flexibility here didn't entail a clear sense of agency over when this work could be taken up and the tension between the times of work and life are clear, particularly when she is responsible for the majority of care for their son. In this narrative Natalia suggests this has resulted in her 'going backwards', revealing the dominant trajectory of 'progress' against which her individualized failure is judged.

I don't work during the day because I don't match with their [employers] timetable for the day, so what I only match is night shifts. So night shifts starts from nine o'clock and I finish at nine in the morning, but with [name of company], they give me a little bit of flexibility, unlike the other company, I can finish at seven in the morning, so that I drive back home, so that I prepare for my son, give him the food and go to school. But it's going to be difficult now again because my son used to be picked up at half past eight, but now he is being picked up at quarter to eight, which is 45 minutes difference, which means if I finish work at seven, I can't drive home, to prepare for him, to feed him and then go to school. So again, I am just going backward. So it's like, I can work weekends, but weekends also, it's hard as well. So I am just picking like one shift a week, which is Saturday night, finish Sunday morning, when his dad is at home, so at least I can get home when he is not going anywhere. So it's really hard... (Female, from Zimbabwe, indefinite leave to remain)

Location of work also intersected with the demands of unpaid care (Hanson and Pratt, 1995). When work was accessed it could be in parts of the region that were not easily accessible and involved a reliance on public transport. Given that some participants would not want to refuse such opportunities, there were clear challenges in managing time in a manner that allowed for a successful combination of these different forms of labour. Here Hannatou raises the difficulties in making journeys across parts of the region and at times where this would be difficult both because of the availability of transport, but also due to clashes with childcare. In these cases the limits on agency are clear, involving, where choices are available, restricted prioritizations.

... sometimes they [recruitment agency] ask me to go in, Newcastle, where, but that is, I want my job in Sunderland or ten minutes of Sunderland because 
This is the accepted version of an article published in Time and Society. For the version of record see: https://doi.org/10.1177/0961463X18778466. To reference: Clayton, J. and T. Vickers (2018) Temporal tensions: European Union citizen migrants, asylum seekers and refugees navigating dominant temporalities of work in England. Time and Society. DOI: 10.1177/0961463X18778466.

I've got kids...this is another issue, if I get a job in Newcastle for example I need to, at six o'clock in the morning it is not easy to go there, not easy, another problem. (Female, 30s, from Guinea, temporary leave to remain).

\section{Reflecting back/looking forward}

We draw attention here to the productive capacity of dominant temporalities as a form of everyday infrastructure in the lives of migrants. We have examined the tensions that emerge where versions and experiences of time clash. In some cases experiences are clearly defined by the constraints set by immigration status, but it is also apparent that there are cases where dominant temporalities cut across such politically constructed categories - primarily through exposure to precarious employment, but also other intersecting dimensions of identity including limited social networks and gendered practices. This has been explored through three key phases as a way of indicating the enduring reach of dominant temporalities of immigration policy, employment practice and gendered relations, into the lives of migrants with various histories, identities and rights.

With reference to work prohibition the experiences of those going through the asylum process is defined by waiting, suspension and uncertain futures. This demonstrates a clear tension between the terms of immigration policy and access to legal paid work for those ready and willing to contribute, which in turn creates stresses in the lives of our participants. Responses variously include opposition, acquiescence, and negotiation including informal paid work and volunteering. Alternative ways of being productive reveal the manner in which dominant temporalities condition subjectivities through the lack of value attached to unwaged labour (James, 1972). While paid work is a moral duty for most, for those prohibited it is a punishable sin (Moore and Forkert, 2014). For a broader sample of our participants, we can see how transitions to work, stratified by immigration status, are dominated by temporalities which often entail violent shifts in the rhythms of compulsion to work with consequences for the type of work taken up. For many this meant entry into paid employment represented a downward trajectory compared to their lives prior to migration to the UK. Whilst there was evidence of progression over time spent within the UK, others were susceptible to becoming stuck in time traps. Lastly, we illustrated the manner in which the unpredictability of labour flexibilisation orders our participant's lives in ways that do not often fit with their needs and the rhythms of their lives beyond the workplace - requiring sacrifice, limited choices and prioritization. The navigation of dominant temporalities that take control away from participants, illustrates some of the key challenges but also more ambivalent stances towards paid employment as both desired and contested. 
This is the accepted version of an article published in Time and Society. For the version of record see: https://doi.org/10.1177/0961463X18778466. To reference: Clayton, J. and T. Vickers (2018) Temporal tensions: European Union citizen migrants, asylum seekers and refugees navigating dominant temporalities of work in England. Time and Society. DOI: 10.1177/0961463X18778466.

Despite some of the shared experiences identified, temporalities are navigated in uneven ways, thus contesting assumptions of a uni-directional linearity of time for migrants as a general category. This relates to the diversity of our sample across politically constructed categories of immigration status. Additionally, some tensions may not be entirely unique to new migrants, or migrant groups. We might particularly think about this with regard to the rise of precarious working conditions. This might allow us to think through where the points of solidarity might align between such groups, whilst recognising that challenges are not experienced uniformly (Jørgensen, 2015). It is also clear that our participants responded to and dealt with the challenges that arose from tensions in different ways based upon their own particular circumstance, migration histories and identities - both acquired and ascribed. There is a spectrum of adaptation and irreconcilability apparent. Some people with more secure status and with families established in the region for example had begun to put down roots and saw their future in the places they were living with aspirations to improve their employment positions. Even if those aspirations had not yet been realized, these was a sense a hope routed through these emerging geographical attachments (Raffaetà, 2015).

We finish with a consideration of migrant futures, which has particular resonance given the current political climate following the recent referendum on the UK's future within the European Union. Despite aspirations mentioned above, for some of our participants from the EU, conditions and experiences of work (and life more generally) will inevitably change. It is this uncertainty and the anxieties this brings (Botterill and Burrell, forthcoming) which characterises the current moment. Whilst recognising that there are certain privileges accrued through whiteness that may give some EU migrants relative (yet limited) protections over those subject to a racializing asylum system (Vertovec, 2017), it is also the case that there are connections around discrimination, uncertainty and anxiety. The uncertainties produced through the asylum system, where the future is often unknown, unpredictable and out of the control, chimes with aspects of this climate, noted by Mezzadra and Neilson (2013: 145) as a 'threat of illegalization [that] hangs over the head of both the asylum seeker and economic migrant'. This demonstrates the role of dominant temporalities in overshadowing the ambitions of migrants in thinking about their future and the way in which some seismic shifts, but also more embedded policies and practices make such temporalities harder to navigate. Despite this gloomy outlook it is crucial to remember that this also creates the conditions through which alliances across differentially included groups may emerge.

\section{References}

Adam B (2004) Time. Cambridge: Polity. 
This is the accepted version of an article published in Time and Society. For the version of record see: https://doi.org/10.1177/0961463X18778466. To reference: Clayton, J. and T. Vickers (2018) Temporal tensions: European Union citizen migrants, asylum seekers and refugees navigating dominant temporalities of work in England. Time and Society. DOI: 10.1177/0961463X18778466.

Anderson B (2007) Battles in time: the relation between global and labour mobilities. Centre on Migration, Policy and Society, Working paper 55. Available at: https://www.compas.ox.ac.uk/media/WP-2007-055Anderson Global Labour Mobilities.pdf (accessed 03/09/17).

Anderson B (2010) Migration, immigration controls and the fashioning of precarious workers. Work, employment and society 24(2): 300-317.

Andersson R (2014) Time and the migrant other: European border controls and the temporal economics of illegality. American Anthropologist 116(4): 795-809.

Andrijasevic R (2009) Sex on the move: Gender, subjectivity and differential inclusion. Subjectivity 29(1): 389-406.

Andrijasevic R and Anderson B (2009) Conflicts of mobility: Migration, labour and political subjectivities. Subjectivity 29(1): 363-366.

Axelsson L, Malmberg B, and Zhang Q (2015) On waiting, work-time and imagined futures: Theorising temporal precariousness among Chinese chefs in Sweden's restaurant industry. Geoforum 78: 169-178.

Baldwin A (2012) Whiteness and futurity: Towards a research agenda. Progress in Human Geography 36(2): 172-187.

Bauder H (2003) 'Brain abuse', or the devaluation of immigrant labour in Canada. Antipode, 35(4): 699-717.

Bloch A (2014) Living in fear rejected asylum seekers living as irregular migrants in England, Journal of Ethnic and Migration Studies 40(10): 1507-1525.

Bloch A and McKay S (2016) Living on the margins: Undocumented migrants in a global city. Bristol: Policy Press.

Botterill C and Burrell K (forthcoming)

Canning V (2017) Gendered Harm and Structural Violence in the British Asylum System. London: Routledge.

Clayton J (2009) Thinking spatially: towards an everyday understanding of inter-ethnic relations. Social and Cultural Geography 10(4): 481-499. 
This is the accepted version of an article published in Time and Society. For the version of record see: https://doi.org/10.1177/0961463X18778466. To reference: Clayton, J. and T. Vickers (2018) Temporal tensions: European Union citizen migrants, asylum seekers and refugees navigating dominant temporalities of work in England. Time and Society. DOI: 10.1177/0961463X18778466.

Clayton J and Vickers T (2017) The contingent challenges of purposeful co-production: researching new migrant employment experiences in the North East of England. Area DOI: 10.1111/area.12409.

Cwerner S B (2001) The times of migration. Journal of Ethnic and Migration Studies 27(1): 7-36.

Cwerner S B (2004) Faster, faster and faster: the time politics of asylum in the UK. Time \& Society 13(1): 71-88.

Datta K, Mcilwaine C, Evans Y, Herbert J, May J and Wills J (2007) From coping strategies to tactics: London's low-pay economy and migrant labour, British Journal of Industrial Relations 45(2): 404-32.

Davies K (2001) Responsibility and daily life: reflections over timespace. In: May J and Thrift N (eds) Timespace: Geographies of temporality. London Routledge, pp.133-148.

Dyer S, McDowell L, and Batnitzky A (2011) Migrant work, precarious work-life balance: What the experiences of migrant workers in the service sector in Greater London tell us about the adult worker model. Gender, Place \& Culture, 18(5): 685-700.

Gedalof I (2007) Unhomely homes: women, family and belonging in UK discourses of migration and asylum. Journal of Ethnic and Migration studies 33(1): 77-94.

Gilroy P (2005) Postcolonial melancholia. New York: Columbia University Press.

Griffiths M, Rogers A, and Anderson B (2013) Migration, time and temporalities: review and prospect. Centre of Migration, Policy and Society Research Resources Paper.

Available at: https://www.compas.ox.ac.uk/media/RR-2013-

Migration Time Temporalities.pdf (accessed 07/03/17).

Griffiths M (2014) Out of Time: The Temporal Uncertainties of Refused Asylum Seekers and Immigration Detainees. Journal of Ethnic and Migration Studies 40(12): 1991-2009.

Hall S (2017) Mooring 'super-diversity' to a brutal migration milieu' Ethnic and Racial Studies 40(9): 1562-1573.

Hanson S and Pratt G (1995) Gender, Work and Space. London: Routledge.

Hargita C S (2016) Disrupting the Hegemonic Temporality of Superannuation. Australian Feminist Law Journal 42(2): 223-240. 
Harvey D (1989) The condition of modernity: an enquiry into the origins of cultural change. Oxford: Blackwell.

Huebener P, O'Brien S, Porter T, Stockdale L, and Zhou Y R (2016) Exploring the Intersection of Time and Globalization. Globalizations 13(3): 243-255.

James S (1972) Wageless of the World, in Sex, Race and Class: The Perspective of Winning. Oakland, CA: PM Press.

Jørgensen M B (2015) Precariat - What it Is and Isn't - Towards an Understanding of What it Does. Critical Sociology 42(7-8): $959-974$.

Latour B (1996) Trains of Thought The Fifth Dimension of Time and its Fabrication. Swiss Monographs in Psychology 4: 173-187.

Lewis H, Dwyer P, Hodkinson S and Waite L, (2015) Hyper-precarious lives: Migrants, work and forced labour in the Global North. Progress in Human Geography 39(5): 580600.

May J, Wills J, Datta K, Evans Y, Herbert J and Mcllwaine C (2007). Keeping London working: global cities, the British state and London's new migrant division of labour. Transactions of the Institute of British Geographers 32(2): 151-167.

Mezzadra S and Neilson B (2013) Border as method, or, the multiplication of labor. London: Duke University Press.

Middleton J (2009) 'Stepping in time': walking, time and space in the city. Environment and Planning A 41(8): 1943-1961.

Moore P and Forkert K (2014) Class and panic in British immigration. Capital \& Class 38(3): 497-505.

Moran D (2012) 'Doing time' in carceal space: timespace and carceal geography. Geografiska Annaler: Series B, Human Geography 94: 305-316.

Pjipers R (2011) Waiting for work: Labour migration and the political economy of borders. In: Wastl-Walter D (ed) Ashgate Research Companion to Border Studies, pp. 417-438. 
This is the accepted version of an article published in Time and Society. For the version of record see: https://doi.org/10.1177/0961463X18778466. To reference: Clayton, J. and T. Vickers (2018) Temporal tensions: European Union citizen migrants, asylum seekers and refugees navigating dominant temporalities of work in England. Time and Society. DOI: 10.1177/0961463X18778466.

Raffaetà, R. (2015) Hope emplaced. What happens to hope after arrival: The case of Ecuadorian families living in Italy, Emotion, Space and Society 16: 116-122.

Refugee Action (2017) Slipping through the cracks: How Britain's asylum support system fails the most vulnerable. Available at: http://www.refugeeaction.org.uk/resource/asylum-support-delays-report/ (accessed 13/09/17)

Robertson S (2015) The temporalities of international migration: implications for ethnographic research. In: S. Castles S, Ozkul D, and Cubas M (eds) Social Transformation and Migration: National and Local Experiences in South Korea, Turkey, Mexico and Australia, pp. 45-60.

Rogaly B (2008) Intensification of workplace regimes in British horticulture: the role of migrant workers, Population, space and place 14(6): 497-510.

Rogaly B and Thieme S (2012) Experiencing space - time: The stretched lifeworlds of migrant workers in India. Environment and Planning A, 44(9): 2086-2100.

Rotter R. (2016) Waiting in the asylum determination process: Just an empty interlude?. Time \& Society, 25(1): 80-101.

Ryan L (2008) Navigating the emotional terrain of families "here" and "there": women, migration and the management of emotions Journal of Intercultural Studies 29(3): 299313.

Shildrick T, MacDonald R, Webster C and Garthwaite K (2012) Poverty and insecurity: Life in low-pay, no-pay Britain. Bristol: Policy Press.

Shubin S (2015) Migration timespaces: a Heideggerian approach to understanding the mobile being of Eastern Europeans in Scotland. Transactions of the Institute of British Geographers 40(3): 350-361.

Sporton D (2013) 'They control my life': the role of local recruitment agencies in East European migration to the UK. Population, Space and Place 19(5): 443-458.

Taylor J (2010) Queer temporalities and the significance of 'music scene' participation in the social identities of middle-aged queers. Sociology 44(5): 893-907.

Tsianos V and Papadopoulos D (2006) Precarity: A savage journey to the heart of embodied capitalism. Transversal Journal 11. Available at: http://eipcp.net/transversal/1106/tsianospapadopoulos/en (accessed: 17/10/17). 
Turnbull S (2016) Stuck in the Middle: Waiting and uncertainty in Immigration Detention. Time and Society 25(1): 61-79.

Vertovec S (2017) Moorings, migration milieus and complex explanations. Ethnic and Racial Studies 40(9): 1574-1581.

Vickers T (2016) Opportunities and Limitations for Collective Resistance Arising from Volunteering by Asylum Seekers and Refugees in Northern England. Critical Sociology 42(3): 437-454.

Vickers, T. et al. (2016). 'New Migrants' in the North East Workforce: Final Report. Nottingham Trent University.

Vickers T and Rutter A (2016) Disposable labour, passive victim, active threat: Migrant/non-migrant othering in three British television documentaries. European Journal of Cultural Studies DOI: 10.1177/1367549416682968.

Virilio P (2006) Speed and politics. Cambridge, Mass: MIT Press.

Waite $L$ (2009) A place and space for a critical geography of precarity? Geography Compass 3(1): 412-433.

Wajcman J (2008) Life in the fast lane? Towards a sociology of technology and time. The British Journal of Sociology 59(1): 59-77.

Wright S (2012) Welfare-to-work, agency and personal responsibility. Journal of Social Policy 41(2): 309-328.

Ylijoki O H (2010) Future orientations in episodic labour: Short-term academics as a case in point. Time and Society 19(3): 365-386.

Yuval-Davis N, Wemyss, G and Cassidy K (forthcoming) Bordering. Cambridge: Polity Press. 